\title{
KABA LAMAMANG TANJUNG AMPALU: SEBUAH PENELUSURAN KEARIFAN LOKAL
}

\author{
Irwanto \\ Balai Bahasa Riau \\ Email: irwantonawar@gmail.com
}

\begin{abstract}
(Title: Kaba Lamamang Tanjung Ampalu: a Search for Local Wisdom). Kaba is a type of oral literature typical of the West Sumatra region, ethnic Minangkabau. Kaba is a story told by a Kabaist with accompaniment of fiddle music. Kaba's literary strength is largely determined by the ability of the Kabaist. Kaba Lamang Tanjung Ampalu is played by Hasan Basril, one of the interesting research subjects to study. Issues of value or local wisdom in Kaba Lamang Tanjung Ampalu are considered interesting and need to be raised. The reason, Kaba as oral literature and values of life as a social phenomenon become an interrelated element. As a human's creation, Kaba will convey the values contained to the audience, so that Kaba can influence the listener's mindset. This reasoning is in accordance with the opinion of Wallek and Warren (1989) that in literature (Kaba) there is a value of life. The descriptive analytical research method explains the meaning of the contents of symbolic interactions that occur in communication events so that the contents of Kaba can be understood appropriately. As a result, this study shows that there are 7 local wisdoms in Kaba Lamang Tanjung Ampalu; the value of local wisdom relates to livelihoods, equipment, values of knowledge, religious systems, arts, social systems, and language and literature.
\end{abstract}

Keywords: kaba, local wisdom, Minangkabau ethnicity

\section{PENDAHULUAN}

Karya sastra adalah ciptaan yang disampaikan dengan komunikatif tentang maksud penulis untuk tujuan estetika. Bisa berupa sebuah kisah, dalam sudut pandang orang ketiga maupun orang pertama, dengan plot dan melalui penggunaan berbagai perangkat sastra yang terkait dengan waktu mereka. Sedangkan, secara etimologi, karya sastra terbentuk dari dua suku kata yaitu karya dan sastra yang menurut KBBI (Kamus Besar Bahasa Indonesia) karya adalah pekerjaan; hasil perbuatan; buatan; ciptaan (terutama hasil karangan), sedangkan sastra adalah bahasa (kata-kata, gaya bahasa) yang dipakai dalam kitab-kitab (bukan bahasa sehari-hari).

Sebagaimana aspek mimetis, karya sastra merupakan cerminan dari kondisi masyarakatnya. Secara etimologi, sastra berasal dari bahasa Sansakerta 'Castra' yang berarti 'petunjuk' atau 'pengarah'. Bila dipadankan dengan kata 'littera' bahasa Latin yang berarti huruf atau pada 'literature' maka padanan tersebut kurang cocok.

Perkerjaan dan hasil perbuatan berupa pemikiran seseorang ini sangat sesuai dengan apa yang dikemukakan oleh Astika (2014). Menurutnya, karya sastra adalah ungkapan pikiran dan perasaan seseorang pengarang dalam usahanya untuk menghayati kejadian-kejadian 
yang ada di sekitarnya, baik yang dialaminya maupun yang terjadi pada orang lain pada kelompok masyarakatnya. Hasil imajinasi dalam bentuk karya inilah menurut Astika yang dihidangkan pengarang kepada pembaca agar dinikmati, dipahami dan diman-faatkan.

Dengan demikian karya sastra bukanlah suatu karangan kosong atau khayalan yang sifatnya tidak sekadar menghibur pembaca saja tetapi melalui karya sastra pembaca akan lebih memahami masalah kehidupan.

Purnami (2017:245) mengungkapkan bahwa sastra lisan kadang ada yang murni dan ada juga yang tidak murni. Sastra lisan murni berupa dongeng, legenda, cerita yang tersebar secara lisan dari masyarakat. Sastra lisan tidak murni biasanya berbaur dengan tradisi lisan. Sastra lisan yang berbaur ini kadang hanya berupa penggalan cerita sakral, seperti cerita yang berasal dari tradisi leluhur yang tak utuh. Menurut Teeuw (1994:28), dalam sastra lisan tidak ada kemurnian sehingga penciptaannya selalu meniru kenyataan dan/atau meniru konvensi penciptaan sebelumnya yang sudah tersedia. Menurut Hutomo (dalam Didipu, 2011:28), sastra lisan memiliki ciri-ciri berikut ini. (1) penyebarannya melalui mulut, maksudnya ekspresi budaya yang disebarkan, baik dari segi waktu maupun ruang melalui mulut, (2) lahir di dalam masyarakat yang masih bercorak desa, masyarakat di luar kota, atau masyarakat.

Waktu terus berjalan, zaman pun berganti. Seiring perkembangan zaman, sastra tidak hanya berbentuk tulisan sebagaimana banyak dipelajari dan ditemui pada literatur-tekstual, tetapi wacana yang bukan aksara dapat dikategorikan sastra: sastra lisan atau yang lebih di kenal dengan istilah folklore. Danandjaja menyebut tradisi lisan sinonim dari folklor lisan (1997: 54). Menurutnya, sastra lisan merupakan bagian kebudayaan yang tersebar dan diwariskan turun-temurun baik yang disertai dengan gerak isyarat atau alat pembantu pengingat.

Terlepas dari bahasan folklor atau bukan, tradisi lisan mempunyai pengaruh dalam pembentukan budaya dan mempertahankannya. Sastra lisan adalah kesusastraan yang mencakup ekspresi kesusastraan warga suatu kebudaya-an yang disebarkan dan dituruntemurunkan sastra lisan (dari mulut ke mulut). Sedangkan sastra tulis berupa karya sastra yang dicetak atau ditulis. Keduanya, baik lisan maupun tulisan, tetap mengandung nilai sastra (nilai estetik). Sebagai bagian dari kebudayaan, sastra lisan tidak lepas dari pengaruh nilainilai yang hidup dan berkembang pada masyarakat.

Pendapat ini serupa dikemukakan oleh Teeuuw dalam sastra lisan tidak ada kemurnian (1994: 28). Menurut Teeuuw, penciptaan sastra lisan selalu meniru kenyataan dan/atau meniru konvensi penciptaan sebelumnya yang sudah tersedia. Sehingga sejalan dengan Sweeney, sifat yang konvensional dan formulaik itu menyebabkan nilai-nilai sosial mengakar dalam kehidupan masyara-kat yang bersangkutan. Dalam analisis Jakobson, setiap tindak komunikasi terdapat enam faktor, salah satunya ialah kode dan kontak. Dengan demikian sastra lisan lebih bersifat komunikatif dan partisipatoris. Dipaparkan bahwa perbedaan utama komunikasi lisan dan tulisan ialah perihal resepsi diperlambat (Luxemburg, 1984: 93).

Pendapat ini makin diperkuat oleh analisis Jakobson. Ditemukan, bahwa setiap tindak komunikasi terdapat enam faktor, salah satunya ialah kode dan kontak. Dipaparkan bahwa perbedaan utama komunikasi lisan dan tulisan ialah perihal resepsi diperlambat (Luxemburg, 1984: 93). Saleh (2007: 128129) membedakan antara lisan dan tulisan

Kaba Lamamang Tanjung Ampalu: Sebuah Penelusuran Kearifan ... (Irwanto) 
dalam tiga hal. Pertama, bentuk komunikasi. Sesuai dengan namanya sastra lisan adalah sastra yang disampai-kan secara lisan dari mulut seorang penyair kepada seseorang atau sekelompok pendengar. Dengan demikian komunikasi antara pengarang dengan penikmat adalah komunikasi langsung. Penikmat sastra lisan dalam satu kesatuan waktu lebih terbatas daripada sastra tulisan. Akibat situasi itu, pengarang akan selalu menyesuaikan diri dengan situasi penikmat.

Menurut Astika (2014), peranan penikmat lebih menonjol bahkan besar kemungkinan bahwa perbedaan situasi penikmat menyebabkan perbedaan penyampaian sastra lisan. Lain halnya dengan sastra tulisan yang merupakan komunikasi tidak langsung antara pengarang dengan pembaca. Dalam satu kesatuan waktu, pembaca tidak terbatas jumlahnya. Karena ia ditulis maka keberadaannya sastra tulisan relatif lebih tetap daripada sastra lisan. Kedua, perkembangan dan keutuhan.

Dari segi perkembangan, sastra lisan tidak stabil. Ketidakstabilan itu terutama disebabkan oleh keinginan pengarang untuk selalu menyesuaikan diri dengan situasi dan kondisi penikmat. Sementara itu, sastra tulisan lebih stabil karena perubahan baru dapat dilakukan apabila karya itu dicetak ulang. Oleh sebab itu keorisinalan sastra tulisan lebih terjamin daripada sastra lisan. Ketiga, dalam hal pemahaman. Reaksi yang muncul dari penikmat amat menentukan kelanjut-an sebuah sastra lisan. Pengarang akan selalu berusaha untuk menarik perhatian penikmat sekalipun untuk itu ia mesti mengubah ceritanya.

Mengutip Astika bahwa sastra lisan tidak stabil dikhawatirkan akan terjadi perubahan dari sastra lisan itu sendiri. Padahal, secara fungsi, sastra lisan dapat membentuk karakter masyarakat karena di dalamnya terdapat pesan-pesan moral. Hal ini sejalan dengan yang disebutkan di dalam buku Folklor Indonesia karya James Danandjaja (1994: 19) bahwa terdapat beberapa fungsi folklor (tradisi lisan). Fungsi folklor adalah (a) sebagai sistem proyeksi, yakni sebagai alat pencermin anganangan suatu kolektif; (b) sebagai alat pengesahan pranata-pranata dan lembaga kebudayaan; (c) sebagai alat pendidikan anak; dan (d) sebagai alat pemaksa dan pengawas agar norma-norma masyarakat akan selalu dipatuhi anggota kolektifnya.

Sastra lisan hidup dan berkembang dalam masyarakat pemiliknya. Indonesia kaya akan sastra lisan. Contohnya, Makyong yang ada di Provinsi Kepulauan Riau. Tradisi ini semula berasal dari Pattani, Muangthai, namun berkembang ke selatan hingga pesisir Melayu. Desfaliana (2016), mengatakan Makyong merupakan pertunjukan teater di mana unsurunsur drama, tari, musik, mimik, dan sebagainya tergabung menjadi satu. Semula, tradisi ini dipertunjukkan di kalangan atas Istana Kelantan dan Riau Lingga hingga tahun 1700-an. Fungsinya bukan untuk menghibur tetapi penghormatan kepada Tuhan Yang Maha Esa. Sultan dan istrinya dianggap wakil Tuhan, maka makyong dianggap persembahan kepada Tuhan. Dalam perkembangannya, makyong berubah menjadi pertunjukan desa sebagai hiburan atau upacara penyembuhan. Kisah yang dimainkan sebagian besar berasal dari warisan cerita-cerita istana kerajaan Melayu, biasanya berbentuk prosa tanpa naskah. Makyong antara lain terdiri atas punakawan (pengasuh) yang mengenakan topeng, wak petanda (ahli pembintangan atau orang bijak), serta para pemain yang semua diperankan oleh kaum perempuan. Salah satu kisah yang paling disukai dalam tradisi makyong adalah dewa muda. Dalam sastra lisan banyak nilai yang bisa ambil. Ada kearifan lokal di dalamnya. 
Kearifan lokal (local wisdom) adalah bagian dari budaya suatu masyarakat yang tidak dapat dipisahkan dari bahasa masyarakat itu sendiri. Biasanya, kearifan lokal diwariskan secara turun temurun dari satu generasi ke generasi melalui cerita dari mulut ke mulut. Kearifan lokal bisa ditemui dalam dalam cerita rakyat, peribahasa, lagu, dan permainan rakyat, upacara adat, tradisi lisan, dll. Secara etimologi, kearifan lokal terdiri dari dua kata, yaitu kata kearifan dan kata lokal. Dalam Kamus Besar Bahasa Indonesia (2011), arti kata arif adalah bijaksana, cerdik dan pandai, berilmu, paham, memahami, mengerti.

Kearifan berarti (1) kebijaksanaan dan (2) kecendekiaan. Berdasarkan pengertian makna dalam kamus tersebut, makna kata arif berkenaan dengan dua hal, yakni (1) karakter atau kepribadian (emosi) dan (2) kecerdasan (kognisi). (Rahyono, 2009: 3). Sedangkan, kata lokal diartikan sebagai setempat. Berdasarkan pengertian tersebut, kearifan lokal adalah segala sesuatu yang bersifat bijaksana, dihasilkan dari sebuah kecerdasan manusia, dan dilaksanakan oleh anggota masyarakat setempat. Kearifan lokal berhubungan dengan mata pencarian, peralatan, nilai pengetahuan, sistem religi, kesenian, sistem kemasyarakatan, dan sistem bahasa dan sastra.

Kearifan lokal juga didefinisikan sebagai pengetahuan dan praktik-praktik yang dapat digunakan untuk menyelesaikan persoalan yang dihadapi dengan cara yang baik dan benar (Bagiya, 2013: 6). Selain itu Sedyawati, menjelaskan bahwa kearifan lokal diartikan sebagai perangkat pengetahuan pada suatu komunitas, baik yang berasal dari generasi sebelumnya maupun pengalamannya berhubungan dengan lingkungan dan masyarakat lainnya untuk mengatasi tantangan hidup (Bagiya, 2013: 7).

Kearifan lokal (local wisdom) berkaitan dengan kecerdasan lokal (local genius) mengacu pada definisi kearifan, yang berarti kecerdasan. Kearifan lokal (local wisdom) pertama kali digunakan oleh Wales dalam tulisannya berjudul "Culture Change in Greater India” (1948), yang kemudian diperluas lagi dalam bukunya berjudul The Making of Greater India: a Study in Southeast Asian Cultures (1951) (Ratna, 2011: 91).

Menurut Wales, local wisdom sebagai "the sum of the cultural characteristics which the vast majority of a people have in common as a result of their experiences in early life". Pokok-pokok pikiran yang terkandung dalam definisi tersebut adalah (1) ciri-ciri budaya, (2) sekelompok manusia sebagai pemilik budaya, serta (3) pengalaman hidup yang menghasilkan ciri-ciri budaya tersebut (Rahyono, 2009: 7). Pokokpokok tersebut menunjukkan bahwa kearifan lokal merupakan kecerdasan manusia yang dimiliki oleh sekelompok (etnis) manusia yang diperoleh melalui pengalaman hidupnya serta terwujud dalam ciri-ciri budaya yang dimilikinya.

Kearifan lokal, local wisdom menurut pemahaman lain sering dikacaukan dengan kebudayaan lokal (local culture). Di samping itu, istilah lain yang juga sering timbul adalah pengetahuan lokal (local knowledge). Indikator tersebut dapat dipergunakan untuk melacak apa yang disebut dengan kearifan lokal, yakni: khazanah pengetahuan yang didasarkan pada pengetahuan lokal, mengalami perubahan dari waktu ke waktu, hidup dan dikenal dalam lingkungan masyarakat tertentu, dan berubah serta dinamis sifatnya. Kearifan lokal selalu berubah seiring dengan kebutuhan masyarakat yang menganut nilai kearifan lokal tersebut.

Dengan demikian, dapat disimpulkan bahwa kearifan lokal adalah seperangkat ide atau gagasan setempat yang dihasilkan dari

Kaba Lamamang Tanjung Ampalu: Sebuah Penelusuran Kearifan ... (Irwanto) 
sebuah kecerdasan manusia yang bersifat bijaksana, digunakan untuk mengatasi berbagai macam persoalan hidup dan dijadikan sebagai pedoman hidup manusia dari waktu ke waktu.

Kearifan lokal juga ada dalam sastra lisan lain, seperti rabab. Rabab merupakan salah satu kesenian musik khas Minangkabauyang diwariskan secara turun temurun dari satu generasi ke generasi selanjutnya, karena rababmerupakansuatu media pembelajaran tentangkearifan budaya yang ada di Minangkabau. Ada beberapa macam jenis dari rababyang tersebar di daerah Minangkabau diantaranya Rabab Darek, Rabab Pariaman, dan Rabab Pasisie. Rabab Pariaman adalah tradisi pertunjukan lisan ini berasal dari Sumatra Barat. Tukang rabab menyampaikan cerita dalam wujud nyanyian dengan ciri dialek Pariaman. Tradisi ini biasa dipertunjukkan pada pesta perkawinan, perayaan nagari, pesta pengangkatan penghulu, dan lain-lain. Cerita yang disampaikan berisi perjuangan untuk mencapai keberhasilan hidup. Tokoh dalam cerita itu menghadapi kesulitan dalam mencapai keberhasilan, kemudian mendapat tanggapan dari penonton. Tidak hanya Rabab di Pariaman, ada juga Rabab Rabab Pasisie, yang hidup di daerah Pesisir Selatan.

Rabab tergolong sebagai sastra lisan Kaba. Kaba adalah sejenis sastra lisan khas dari daerah Sumatra Barat, etnik Minangkabau. Kaba merupakan cerita yang disampaikan oleh tukang Kaba dengan iringan gesekan musik rabab. Kekuatan sastra Kaba sangat ditentukan oleh kemampuan tukang Kaba. Kaba Lamang Tanjung Ampalu dimainkan oleh tukang Kaba bernama Hasan Basril, menjadi salah satu obek penelitian yang menarik untuk diteliti. Yesi dkk., (2012, mengungkap adanya nilai-nilai moral yang terdapat dalam Kaba pada kesenian rabab di nagari Duku Kecamatan Koto XI Tarusan. Juga ada penelitian Agnes, Novita,
(2017) soal Kesenian Rabab Sebagai Media Pembelajaran (Praktik Komunikasi Generasi Muda yang Menyaksikan Rabab dengan Perabab Melalui Kaba Lamang Tanjuang Ampalu di Kec. Kuranji Kota Padang).

Kedua penelitian tersebut menemukan nilai moral dan praktik komunikasi yang terjadi antara perabab dengan anak muda yang menyaksikan rabab yang terkesan kurang menghibur. Akan tetapi, belum ada penelitian soal Kaba Lamang Tanjung Ampalu sebagai sebuah penelusuran kearifan lokal. Maka, akan lebih menarik jika Kaba Lamang Tanjung Ampalu dijadikan sebagai objek penelitian. Perntanyaan penelitian yang tepat untuk objek penelitian ini adalah; nilai-nilai keariaman lokal apa yang terdapat dalam Kaba Lamamang Tanjung Ampalu?. Sedangkan tujuan dari penelitian ini adalah untuk mengetahui nilainilai keariaman lokal apa yang terdapat dalam Kaba Lamamang Tanjung Ampalu.

Pemilihan objek ini tentu disebabkan oleh Kaba sebagai sastra lisan dan tata nilai kehidupan sebagai fenomena sosial menjadi sebuah elemen yang saling berkaitan. Sebagai buah cipta manusia, Kaba akan menyampaikan nilai-nilai yang termuat kepada masyarakat penikmat, sehingga Kaba bisa memengaruhi pola pikir pendengar. Alasan ini sesuai dengan pendapat Wallek dan Warren (1989) bahwa di dalam sastra $(K a b a)$ terdapat nilai kehidupan. Dengan metode penelitian deskriptif analitis menjelaskan makna isi interaksi simbolik yang terjadi dalam peristiwa komunikasi sehingga dapat dipahami isi Kaba secara tepat.

\section{METODE}

Metode merupakan prosedur atau rangkaian cara yang sistematik dalam menggali kebenaran ilmiah. Dengan menggunakan metode yang tepat, maka akan diperoleh jawaban dari permasalahan yang diteliti. 
Bahkan, dengan metode yang tepat maka akan diperoleh hasil penelitian yang memiliki validasi yang tinggi. Metode yang digunakan dalam penelitian ini adalah metode kualitatif. Metode kualitatif adalah metode pengkajian atau metode penelitian suatu masalah yang tidak didesain atau dirancang menggunakan prosedur-prosedur statistik.

Metode kualitatif mempunyai sifat deskriptif.yakni, data yang telah terkumpul dan dicatat dalam kertu data kemudian dianalisis berdasarkan teori yang dipakai data yang di catat berwujud kata, kalimat, wacana, dan lain-lain.data yang digunakan dalam penelitian ini yakni rekaman penampilan kaba dengan iringan musik rabab, berjudul "Lamang Tanjung Amapalu" dimainkan oleh perabab (tukang rabab) bernama Hasan Basil dalam unggahan video di Youtube berdurasi 4 jam, 53 menit. Video ini dipublikasikan oleh Amigo93 pada 10 Januari 2019. Adapun hal yang menjadi bahan pertimbangan dalam menjadikan Youtube sebagai sumber data dalam penelitian ini adalah karena faktor efektifitas. Ini diperkuat oleh Burke, 2009, dalam Ena Teda, YouTube bisa menjadi sumber belajar dan media pembelajaran yang bisa memenuhi tuntutan kebutuhan generasi digital. YouTube juga akan menjadi perpustakaan video gratis yang sangat luas bagi pembelajar.

Rekaman video dijadikan sebagai data primer yaitu data yang terkait langsung dengan permasalahan yang diteliti atau data yang diperoleh secara langsung dari penelitian lapangan mengenai nilai kearifan lokal yang terdapat dalam kaba pada pertunjukan kesenian rabab, yang dimainkan Hasan Basri dan data sekunder yang merupakan data pendukung yang relevan dengan permasalahan penelitian catatan, laporan atau dokumendokumen tertulis, laporan-laporan, catatan dan buku-buku yang relevan dengan penelitian ini.

Sedangkan teknik analisis yang dipakai dalam penelitian ini adalah analisis data secara induktif. Induktif berarti proses mengambil suatu kesimpulan dari hal-hal yang bersifat khusus menjadi kesimpulan yang bersifat umum.

Dalam penelitian kualitatif, peneliti berusaha mengumpulkan fakta dari fenomena atau peristiwa-peristiwa yang bersifat khusus, kemudian berdasarkan fenomena atau peristiwa yang bersifat khusus tadi, diambil kesimpulan yang bersifat umum. Analisis data adalah proses mencari dan menyusun secara sistematika data yang diperoleh dari hasil dokumentasi kedalam unit-unit, melakukan sinestesa, dipelajari, dan membuat kesimpulan sehingga mudah dipahami oleh diri sendiri maupun orang lain. Proses analisa dilakukan pada objek peneliti dengan cara mengamati visualisasi dalam setiap narasi lisan dalam rekaman. Aktifitas yang dilakukan pada tahapan analis data adalah reduksi data, tampilan data, dan penarikan kesimpulan/ verifikasi, (Sugiyono, 2012: 89-91). Terakhir, data yang dianalisis akan dituangkan dalam bentuk teks berupa kata-kata. Menurut Mahsun (2005:233) penelitian kualitatif deskriptif adalah penelitian yang menghasilkan data deskriptif berupa kata-kata bertujuan untuk memahami fenomena sosial termasuk fenomena kebahasaan.

\section{HASIL DAN PEMBAHASAN}

Temuan observasi kearifan lokal dalm cerita Kaba "Lamang Tanjung Amapalu" (LTA) yang dimainkan oleh Hasan Basri ada dalam beberap hal;

\section{Peralatan Kehidupan Manusia}

Merujuk pada pendapat ahli, salah satu poin dalam kearifan lokal adalah adanya 
peralatan kehidupan. Peralatan hidup dalam Kaba LTA sangat identik dengan profesi sesorang yang hidupdi kampung. Umumnya mereka berprofesi sebagai petani, pekerja hutan, pedagang dan juga berprofesi sebagai dokter. Ini terlihat dalam teks.

\section{Jo Apo karajo bapak Gazali, pai maarik} kayu nyo ka rimbo

Coitu bana samaso itu, maklum maarik kayu, kadang saminggu di dalam rimbo

Kadang sampai yo limo baleh hari...

Nan tumpak di mande nan di rumah

Yo apa karajo si umia, dicubo mambuek lamang, Dibao ka pasa rami, jo lamang iduak $k a$ disambuang, Jo lamang bareh ka dibali. Jo itu anak bagadangkan.

Dalam baris pertama ada kata kata pekerjaan Gazali yang menghidupi anaknya dengan memotong kayu di hutan dengan "arik". "Arik" yang berarti gergaji besar untuk memotong pohon di hutan. Peralatan ini dipakai para pekerja hutan untuk memotong kayu. Sekarang peralatan tersebut sudah digantikan dengan mesin sensaw. Selanjutnya, istri Gazali, yaitu umi Mia, berprofesi sebagai pembuat lemang. Lemang dibuat secara tradisonal, yaitu dibakar pakai bara api. Dalam proses pembuatan lemang juga ada bambu, daun pisang sebagai cetakan pembuat lemang. Setelah lemang dibuat, ibu Mia menjualnya ke pasar. Hasilnya akan digunakan untuk membeli beras bagi anak-anak mereka.

\section{Mata Pencarian}

Dalam cerita ini ditemukan berbagai profesi sebagai mata pencarian masyarakat. Ada Zaidin yang berprofesi sebagai dokter. Zaidin menjadi dokter dengan menempuh berbagai kesulitan hidup. Dia dibesarkan oleh seorang orang tua angkat yang berprofesi sebagai pedagang. Orang tua kandung Zaidin sendiri adalah seorang petani dan pedagang lemang di daerah Solok, Padang Panjang dan Bukitiinggi. Berdagang sudah menjadi mata pencarian dan profesi khas orang Minang, baik di kampung atau pun di daerah rantau. Bertani yang dilakoni mertua Zaidin juga mejadi ciri khas daerah agraris. Mereka menekuni pekerjaan sebagai petani, berladang, dan mencari kayu ke hutan disebabkan tuntutan kehidupan.

\section{Sistem Kemasyarakatan}

Sistem kemasyarakatan merupakan perangkat atau unsur-unsur yang terdapat di dalam suatu masyarakat. Sistem kemasyarakatan meliputi sistem kekerabatan, organisasi, sosial, dan politik. Dalam Kaba LJA sistem kemasyarakatan yang diceritakan adalah masyarakat suku Minang. Di dalam masyarakat Minang terdapat nilai kearifan lokal yaitu adat gotong royong. Gotong royong merupakan sebuah nilai kearifan lokal yang telah diwariskan oleh nenek moyang. Gotong royong merupakan sikap saling tolong menolong dan bekerja sama dalam menghadapi permasalahan hidup. Dalam masyarakat pedesaan terdapat beberapa kegiatan yang biasanya dilakukan secara bergotong-royong. Ini bisa dilihat dalam Kaba LTA waktu mobil Dokter Zaidin masuk parit. Mobilnya bisa kembali ke jalan raya karena ditolong oleh kelurga petani. Akhirnya, Zaidin membalas kebaikan orang tua Nurhaya dengan menikahinya. Inilah cara Zaidin membalas kebaikkan orang lain yang sudah membantunya lepas dari masalah.

\section{Sistem Bahasa dan Sastra}

Secara sederhana, bahasa dapat diartikan sebagai alat untuk menyampaikan sesuatu yang terlintas di dalam hati. Namun, lebih jauh bahasa bahasa adalah alat untuk 
beriteraksi atau alat untuk berkomunikasi, dalam arti alat untuk menyampaikan pikiran, gagasan, konsep atau perasaan. Dalam Kaba LTA, bahasa yang dipakai merupakan bahasa Minang. Tukang cerita menyampaikan dengan iringan musik rabab. Ada alur cerita yang jelas dari awal hingga akhir, ada tokoh, ada setting tempat di daerah Padang, Solok, Sijunjung, Palembang, Padangpanjang, dan Bukitinggi.

\section{Nak urang taluak sikaduduak \\ Ka plang jinjiang lah ikan \\ Tingga dunsanak sadang duduak \\ Talieak tanjung ampalu \\ Di sijunjuang tampek kajadiannyo}

Tek diatas diartikan; Anak orang teluk sikaduduk, Kepalang jinjing lah ikan, Tinggal saudara sedang duduk, Lihat Tanjung Ampalu. Di Sijunjung tempat kejadiannya. Bahasa dalam kutipan tek ini jelas sebagai bahasa Minang sebagai media pengantar cerita kepada penikmat Kaba LTA. Si tukang Kaba (Hasan Basri) menguasai bahasa moinang dengan penuh dan tahu betul akan kebutuhan masyarakat penuntonnya yang mayoritas orang Minang. Sedangkan, cara penceritaan, selain berdendang, ada juga pantun seperti teks diatas.

\section{Kesenian}

Cerita Kaba LTA disampaikan dengan menggunakan alat musik rabab. Rabab alat yang berbentuk seperti biola. Jika biola dimainkan sambil berdiri, bagian cembungnya ditekankan dibawah dagu sementara tangan kiri memegang ujungnya dan sekaligus memetik nada dan tangan kanan memegang alat penggeseknya, maka alat musik rabab digunakan sambil duduk, bagian cembungnya ditekankan ke lantai, sementara tangan kiri tukang rabab memegang bagian ujungnya sambil memetik nada-nada dan tangan kanan menghasilkan alat penggesek yang menghasilkan bunyi yenak didengar.

Seriring dengan perkembangan zaman, Kaba dengan musik rabab, sekarang mengalami perubahan. Tidak hanya diringi rabab, juga ada gendang sebagai pelngkap kesenian tradisional orang pesisir di Sumatra Barat ini.

Kaba LTA dimainkan dalam kurun waktu 4 jam, 53 menit. Hampir lima jam dinutuhkan untuk melakukan pertunjukan yang menghibur ini. Biasanya rabab diaminkan pada malam hari, mulai dari siap sholat isya hingga subuh. Lamanya waktu pertunjukan cenderung dipengaruhi pula oleh suasana pertunjukan, respon dari khalayak. Tempat pertunjukan ada di lapangan terbuka, ada juga dalam ruangan tertutup. Dalam pertunjukan rabab ada jarak antara pemain rabab dengan khalayak.

\section{Sistem Pengetahuan}

Sistem pengetahuan dalam cerita Kaba LJA cakupannya cukup luas dan banyak. Terdapat dalam setiap cerita yang mengajarkan seseorang untuk bisa bertahan hidup. Ini dimulai dari perjalanan Zaidin yang berperan sebagai tokoh utama dalam cerita ini yang pergi meningalkan kampung halamnnya. Sebelum berangkat dari rumah, Zainudin makan di rumah hingga kenyang dan mengambil uang yang ada dalam kontong ibunya. Tidak semua, uang dibawa pergi oleh Zaidin. Dinggalkannya satu sen untuk kebutuhan ibu dan adik-adiknya. Pemikiran ini sangat bijak. Dia pergi minggalkan rumah tanpa sepengetahuan orang tua, bukan tanpa bekal. Akan tetapi, dia pergi dengan bekal uang. Ini menunjukan sebuah kecerdasan yang baik ditunjukan Zaidin.

Setelah capek berjalan kaki, Zaidin mencoba naik bus barang, dan mengaku

Kaba Lamamang Tanjung Ampalu: Sebuah Penelusuran Kearifan ... (Irwanto) 
sebagai anak yatim. Ini juga dilakukan Zaidin di tempat tujuan, yaitu di Padang dalam mencari orang tua angkat. Dipercaya, sebagai pedagang, Zaidin yang cerdas pun melanjutkan sekolah di kelas tiga bersam dengan adiknya, Ramuna. Ramuna anak dari ibu angkatnya. Hinga akhirnya, Zaidin mendapat gelar dokter. Dalam prosesnya, Zaidin diajarkan banyak hal dalam berdagang. Diajarkan satu, dua didapat. Diberi dua, diga diperoleh. Itulah cerdasnya Zaidin dalam bertahan hidup, hingga disayang oleh orang tua angkat. Ini bisa dilihat dalam tek berikut;

Anak sarupo jo anak balam. Ciek jantan, surang padusi

Kok sakola samo sakola, kok pulang samo pulang

Balanjo samo balanjo. Sanang ati indak tabado

Den bilang buyuang si Zaidin, urang pandai bana bande angkek.

Kok dietong gagang Zaidin. Ciek diaja, duo dapek

Duo diaja, tigo tantu. Sanang ati bapak jo mande.

Dalam tek tersebut terlihat jelas bahwa Zainudin anak yang cerdas. Kepintarannya melampaui dari pelajaran yang diberikan padanya. "Kok dietong dagang Zaidin. Ciek diaja, duo dapek. Duo diaja, tigo tantu. Sanang ati bapak jo mannde" Ini diartikan; "Kalau dihitung sebagai pedagang. Satu diajarkan, dua yang didapat. Dua diajarkan, tiga yang dikuasai. Senanglah hati ibu dan bapaknya."

\section{Sistem Religi}

Cerita Kaba LTA sangat menonjolkan nilai-nilai agama. Zaidin digambarkan sebagai anak yang patuh, penurut, santun dan taat menjalankan ibadah agama. Ini bisa dilihat dalam tek;

Oooado lah pado suatu ari, sawakatu abak dalam rimbo,

hari minggu si zaidin perai basikola

Mande bakato ka anak kanduang,

ooo nak kanduang si zaidin, kan iyo ari minggu

Waang perai basikola, kakak ang sadang di sawah,

tolong antakan nasi, kakak ang Zaidin oiiii

Oi aciak caronyo tanjuang ampalu, baitu bana maso itu

Tumpak dek buyuang si zaidin anaknyo haromat,

sopan santun, anak ko patuah $k a$ mandenyo

Kalu co itu, tarah papan, ditarah makok kadibali

Kalau co itu dikatokan, lai samo sanang di dalam ati

Nyo bao nasi, jo cerek, cerek nyo jinjiang jo tangan kida

Ooo nasi nyo jinjiang jo nan suaok, bajalan buyuang si zaidin manuju $k a$ tangah sawah

Pada pertengah tek ada kata:

"Tumpak dek buyuang si zaidin anaknyo haromat,

sopan santun, anak ko patuah ka mandenyo".

Artinya, Terlihat si anak Zaidin, orangnya hormat, span santun, anaknya patuh ke ibunya."

Nilai religi juga ada pada saat Zaidin sudah sukses di rantau. Dia menjadi dokter. Dicobanya pulang ke kampung daerah Tanjung Ampalu untuk melihat keluarganya. Akan tetapi, tidak seorang pun keluarganya 
diemuinya. Hanya gubuk buruk kosong yang didapatnya. Tidak ada informasi tentang orang tua, kakak, dan adiknya. Ini menunjukan cara Zaidin membalas jasa orang tuanya. Upaya mencari keluarganya terus dilakukan. Hingga pada akhirnya, didaptnya kedua orang tuanya di Bukitinggi dalam kondisi susah yang berprofesi sebagi penjual lemang. Dia bersujut dan bersimpuh menagis di hadapan ibu dan bapaknya meminta maaf karena sudah meninggalkan rumah. Pencarian anggota keluarga, yaitu adik perempuannya, Norma juga dilakukan. Ini karena rasa sayangnya pada Norma dan ingin membahagiakannya. Namun, apa yang terjadi. Zaidin menemui adiknya dalam kondisi sekarat dan Norma menitipkan seorang anak laki-laki bernama Salman pada Zaidin.

Nilai religi lain juga ditunjukkan Zaidin kepada orang tua angkatnya, dengan selalu mengunjungi dan membahagiakan mereka. Bahkan, adik perempuannya dari ibu angkatnya dicarikan jodoh, seorang sahabat karibnya dan berprofesi sebagai dokter di Palembang. Inilah bakti Zaidin pada orang tua angkatnya. Nilai religi secara teori cakuman cukup luas. Didalamnya juga ada nilai tolong menolong dan nilai solidaritas. Untuk nilai tolong menolong adalah saat mobil Zaidin melalami musibah masyarakat secara spontan menolongnya. Sedangkan nilai solidaritas ada pada nilai persahabatan antara Zaidin dengan sahabatnya, seorang doter bernama Abdul Munab yang bertugas di Palembang. Abdul Munab menkahi adik Zaidin bermana Ramuna dengan alasan solidaritas dan menjaga persahabatan. Ini bisa dilihat dalam tek;

Kalau ang ndak namuah kawin dengan Ramuna,

mulai bakarek rotan badan awak Jangan ambo ang sako dunsanak lai, putuihkan kito badunsanak

Putuihkan kito badunsanak

Tak dapek bantu mambantu, tak dapek tolong manolong

Bapikialah Munab katiko itu..dan manarimo permintaan Zaidin

Artinya;

Kalau kamu tidak mau dengan Ramuna, maka persahabatan kita akan potong rotan. Usah saya kamu anggap saudara lagi, putuskan kita bersaudara. Potong rotan diartikan sebagai putusnya persahatan. Akhirnya, Romuna menerima permintaan Zaidin.

Kutipan itulah yang akhirnya menguatkan Abdul Munap menikahi Ramuna. Ini dinilai sebagai nilai solidaritas dalam cerita Kaba LTA.

\section{SIMPULAN}

Hasil penelitian menujukan ada tujuh nilai kearifan lokal yang ditemukan dalam Kaba Lamang Tanjung Ampalu yang dimainkan oleh tukang rabab, Hasan Basril. Nilai kearifan tersebut adalah; Pertama, adanya nilai kearifan lokal dalam peralatan Kehidupan Manusia. Peralatan hidup dalam Kaba LTA sangat identik dengan profesi sesorang yang hidup di kampung. Umumnya mereka berprofesi sebagai petani, pekerja hutan, pedagang dan juga berprofesi sebagai dokter. Semua profesi tersebut memerlukan alat yang memiliki nilai kearifan lokal. Petani identik dengan peralatan cangkul, parang, dll. Sedangkan pencari kayu sangat familiar dengan gergaji, kampak dan alat lainnya.

Kedua, sistem mata pencarian. Banyak perbedaan cara hidup orang desa dengan kota, antara masyarakat modern dengan masyarakat tradisional. Dalam cerita Kaba LJA, Zaidin 
memainkan peran sebagai seorang dokter, Umi Mia sebagai pedagang lemang, dan Gazali berprofesi sebagai pencari kayu di hutan. Ketiga, sistem kemasyarakatan. Di dalam masyarakat Minang terdapat nilai kearifan lokal yaitu adat gotong royong. Gotong royong merupakan sebuah nilai kearifan lokal yang telah diwariskan oleh nenek moyang. Gotong royong merupakan sikap saling tolong menolong dan bekerja sama dalam menghadapi permasalahan hidup. Keempat, sistem bahasa dan sastra. Dalam Kaba LTA, bahasa yang dipakai merupakan bahasa Minang. Tukang cerita menyampaikan dengan iringan musik rabab. Ada alur cerita yang jelas dari awal hingga akhir, ada tokoh, ada latar setting tempat di daerah Padang, Solok, Sijunjung, Palembang, Padangpanjang, dan Bukitinggi.

Kelima, kesenian. Cerita Kaba LTA disampaikan dengan menggunakan alat musik rabab. Rabab alat yang berbentuk seperti biola. Keenam, sistem pengetahuan. Dipercaya, sebagai pedagang, Zaidin yang cerdas pun melanjutkan sekolah di kelas tiga bersam dengan adiknya, Ramuna. Ramuna anak dari ibu angkatnya. Hinga akhirnya, Zaidin mendapat gelar dokter. Dalam prosesnya, Zaidin diajarkan banyak hal dalam berdagang. Sedangkan ketujuh adalah adanya nilai religi. Buktinya, Zaidin digambarkan sebagai anak yang patuh, penurut, santun dan taat menjalankan ibadah agama.

Dengan demikian, maka ada fungsi utama kearifan lokal sebagai pendukung kearifan nasional. Kearifan lokal merupakan semen pengikat berbagai bentuk kebudayaan yang sudah ada sehingga disadari keberadaannya. Oleh karena ia lahir melalui dan hidup di dalam semesta yang bersangkutan, maka kearifan lokal diharapkan dapat dipelihara dan dikembangkan secara optimal.

\section{DAFTAR PUSTAKA}

Amigo93 (2019 Januari 10). https://www. youtube.com/watch? $\mathrm{v}=\mathrm{HcGFCrHrLRQ}$

Burke, S.C., Snyder, S., Rager, R.C. 2009, dalam e-jurnal.usd.ac.id "An Assessment of Faculty Usage of YouTube as a Teaching Resource". The Internet Journal of Allied Health Sciences and Practice. Vol. 7 No. 1, available online at http:// ijahsp.nova.edu

Bagiya, U. F, dkk. (2013). "Kearifan Lokal Bahasa dan Budaya Nelayan Pantai Selatan Kabupaten Purworejo". Universitas Muhammadiyah Purworejo.

Danandjaja, J. (1997). Folklor Indonesia: Ilmu Gosip, Dongeng, dan Lain-lain. Jakarta: Grafiti.

Desfaliana. (2016). Analisis Nilai-Nilai Budaya Melayudalam Teater Makyong, Universitas Maritim Raja Ali Haji, Tanjungpinang.

Purnami. (2017). Asal-Usul Reog: Sastra Lisan Sindiran Birokrasi pada Masanya. journal.unesa.ac.id/index.php/ paramasastra

Rahyono, F. X. (2009). Kearifan Budaya dalam Kata. Jakarta: Wedatama Widya Sastra.

Sastra Lisan; Teori dan Penerapannya,oleh I Made Astika, S.Pd., M.A.; I Nyoman Yasa, S.Pd., M.A. Graha Ilmu, Yogyakarta Sugiyono. (2012). Memahami Penelitian Kualitatif". Bandung: ALFABETA.

Taum, Y. Y. (2011). Studi Sastra Lisan: Sejarah, Teori, Metode, dan Pendekatan Disertai Contoh Penerapannya. Yogyakarta: Lamalera.

Wallek dan Warren (1989). Teori Kesusastraan. Jakarta. PT. Gramedia. 